\title{
Superconducting Devices for Power Engineering
}

\author{
T. Janowski ${ }^{a, *}$, B. Kondratowicz-KuCEWiCZ ${ }^{a}$, G. Wojtasiewicz ${ }^{a}$, S. KOzAK ${ }^{a}$, \\ J. KOZAK ${ }^{a}$, M. MAJKA ${ }^{a}$ AND L. JAROSZYŃSKI ${ }^{b}$ \\ ${ }^{a}$ Electrotechnical Institute, M. Pożaryskiego 28, 04-703 Warsaw, Poland \\ ${ }^{b}$ Lublin University of Technology, Nadbystrzycka 36D, 20-618 Lublin, Poland
}

\begin{abstract}
The paper presents the current state of research on superconducting devices for the electrical power system, i.e. transformers, fault-current limiters, and energy storages. In particular, it describes scientific achievements of the Laboratory of Superconducting Technologies of Electrotechnical Institute. The development of distributed and renewable energy sources, as well as the increasing number of receivers with low power factor will rise interest in superconducting fault-current limiters and superconducting transformers rated below 1 MVA. Previous studies were focused on the largest power transformers and highest current superconducting fault-current limiters. ReBCO coated conductors allow to build efficient superconducting AC devices. Superconducting tape of a layered structure (second generation HTS tape) enables the construction of transformer rated up to a few MVA without the usage of parallel conductors. Relatively high resistance of the tape in normal state allows to build fault-current limiters and fault-current limiting transformers. Superconducting transformers and superconducting fault-current limiters can help to increase connected power of distribution stations and thereby accelerate development of renewable energy sources.
\end{abstract}

DOI: 10.12693/APhysPolA.130.537

PACS/topics: 74.90.+n, 84.60.Ve, 84.70.+p, 84.71.-b, 84.71.Ba, 84.71.Mn, 85.25.-j, 85.25.Am, 85.25.Qc

\section{Introduction}

Power system including generation, transmission and distribution of electricity works using alternating sinusoidal current at the frequency of 50 or $60 \mathrm{~Hz}$. The choice of such current was dictated by the possibility to accomplish the long-distance transmission of electricity at low losses. Power of an electric equipment or machinery is a function of its dimensions to the fourth power $\left(P=f\left(l^{4}\right)\right)$, whereas power losses are a function of the dimensions to the third power $\left(\Delta P=f\left(l^{3}\right)\right)$. That is why, the larger devices are, the higher their efficiencies. For this reason, there is the constant tendency to increase the power of individual generators and transformers.

Due to technological reasons, the nominal voltages of currently built generators do not exceed $30 \mathrm{kV}$. The nominal voltage of transmission lines can reach up to $1000 \mathrm{kV}$. Voltage is reduced or increased by transformers. In the power system, installed capacity of transformers is about four times greater than the sum of generator power. Despite the high efficiency, transformers are responsible for about $10 \%$ of the energy losses. Power losses of conventional transformers are generated in steel core and in copper windings transporting current. At nominal load, winding losses are about four times larger than core losses $\left(\Delta P_{\mathrm{Cu}}=(3.5-5.0) \Delta P_{\mathrm{Fe}}\right)$. Winding losses in the superconducting transformer are very low. The problem of power losses and efficiency of superconducting transformers was considered in several papers [1]. All the works show that superconducting transformers are more efficient. Due to the high price of $\mathrm{ReBCO}$ wires, the payback

\footnotetext{
${ }^{*}$ corresponding author; e-mail: t.janowski@pollub.pl
}

time of superconducting device is long. Besides increased efficiency, superconducting transformers have many advantages such as: ability to limit short-circuit currents, low output voltage regulation under variable load or high overload endurance.

The new situation is created by the development of distributed and renewable energy sources, advancements in cryogenic cooling and remote control techniques. These facts cause an increasing interest in transformers with power rating below 1 MVA.

Superconducting fault current limiters (SFCL), which are $\mathrm{AC}$ devices, work with large currents and with very low voltages $(\approx 1 \mathrm{~V})$ during stand-by. Research on SFCLs is very advanced. The three-winding inductive-type coreless SFCL are described in the article [2]. It has been built on the basis of patent P.400335 entitled "Superconducting fault current limiter".

Superconducting energy storages (SMES) are DC devices, where electromagnets can be made of any available superconducting wire, low-temperature superconductors (LTS) or high-temperature superconductors (HTS). SMESs are available commercially. The energy stored in the magnetic field is too small to effectively stabilize the power grid. However they can efficiently protect electrical appliances from power failures. In the article [3, 4], YBCO HTS SMES built in Electrotechnical Institute in Warsaw is reported. This device may be refrigerated using liquid nitrogen or a cryocooler.

\section{Superconducting magnetic energy storage}

The demand for energy supplied to the power energy system is variable over time due to daily fluctuations and seasonal changes.

Application of the sources characterized by high uncertainty of work, such as renewable energy sources (RES) 
exacerbates the volatility of electricity consumption in power system. Power increase of RES and their prevalence in many countries is the reason for the search for new technical solutions to stabilize the system. The variability of power generated by wind turbines and photovoltaic causes increased interest in energy storage technology.

The concept of superconducting energy storage (SMES) is based on phenomena which do not apply to other energy storage technologies: superconducting materials can conduct electricity without resistive losses; an electric current produces a magnetic field as a form of clean energy that can be stored.

The combination of these features enables to build highly efficient electric energy storage devices based on superconducting windings. Functionally SMES is different from other energy storage technologies because the stored energy is generated by a continuous flow of current in the superconducting coil. Furthermore, the transformation of alternating current $\mathrm{AC}$ to direct $\mathrm{DC}$ and $\mathrm{DC}$ to $\mathrm{AC}$ is the only one conversion process in a SMES system. As a result of it, there is no thermodynamic losses associated with converting one form of energy to another.

The operation of SMES system can be divided into three stages: charging coil from the power network through a power conversion system (PCS); state of waiting, when the coil is not powered on, and current flows without loss and a step of discharging the coil into the network through the PCS system. After discharging the winding returns to the superconducting state and energy accumulation.

The first SMES were designed to storage energy greater than 5000 MWh. This idea was realized by the construction of solenoid coils with a $1 \mathrm{~km}$ diameter. It was only in the eighties of the twentieth century industrial enterprises have noticed the benefits from the use of SMES and joined to the construction of these devices.

Projects and realizations of industrial applications of superconducting energy storage devices developed in recent years include three groups: SMES with energy values about MJ partly in the phase of commercialization, devices with energy reaching GJ, which are still in studies design and construction, as well as HTS SMES with the small energies in the range of $\mathrm{kJ}$ whose technology still requires research (Table I).

Initial work on SMES in Poland was taken in Superconducting Technology Laboratory in Electrotechnical Institute in Lublin (research project 4 T10A 00425 supported by State Committee for Scientific Research and NN5100855330 supported by the Ministry of Science and Higher Education) [3]. The HTS superconducting electromagnet for energy storage system was designed and built (Fig. 1).

The magnet consists of 7 double-pancake coils, each one made of 14 pieces of HTS Bi2223/Ag high strength stainless-steel laminated. The tape was made by American Superconductor. The magnet support is made of aluminium alloy 6063. Coils are insulated by Kapton
TABLE I

Selected SMES devices built on the world [5]

\begin{tabular}{c|c}
\hline \hline $\begin{array}{c}\text { company } \\
\text { country }\end{array}$ & $\begin{array}{c}\text { superconductor } \\
\text { energy }\end{array}$ \\
\hline Los Alamos Laboratory & $\mathrm{NbTi}$ \\
USA & $\mathrm{MJ}$ \\
\hline American Superconductor & $1-5 \mathrm{MJ}$ \\
USA & Bi2212, $1 \mathrm{MJ}$ \\
\hline Chubu Electric Power & $\mathrm{Bi} 2223$ \\
Japan & $10 \mathrm{~kJ}$ \\
\hline Univ. of El. Sci. and Techn. & $\mathrm{Bi} 233 / 600 \mathrm{~kJ}$ \\
\& Innopower Corp., China & $\mathrm{Bi} 2223$ \\
\hline Korean Electric Res. Inst. Korea & $150 \mathrm{~kJ}$ \\
\hline ACCEL Instr. & $\mathrm{Bi} 2223$ \\
Germany & $34.8 \mathrm{~kJ}$ \\
\hline Electrotechn. Institute & $\mathrm{Bi} 2223$ \\
Poland & $2.48 \mathrm{~kJ}$
\end{tabular}

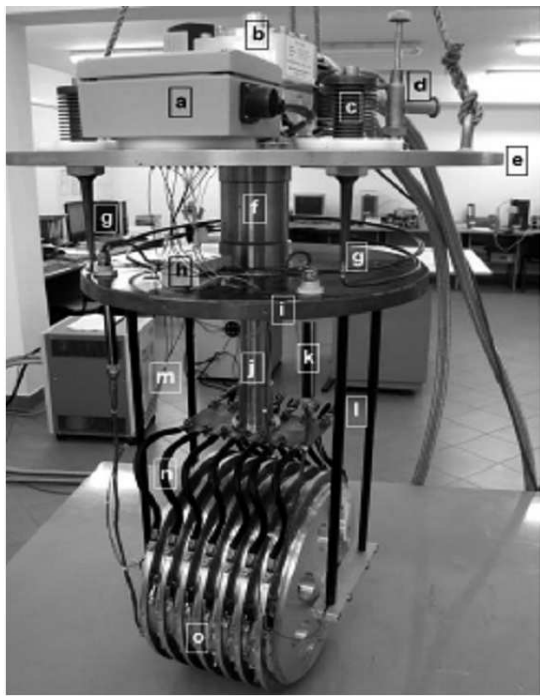

Fig. 1. Assembly of the SMES magnet: a - instrumentation socket, b - cryocooler cold head, c - current connector, $\mathrm{d}$ - vacuum connector, e - cryostat cover, $\mathrm{f}$ - 1st stage of cold head, $\mathrm{g}$ - copper current leads, $\mathrm{h}$ - thermalisation aluminium block, $\mathrm{i}$ - thermal shield cover, $\mathrm{j}-2 \mathrm{nd}$ stage of cold head, $\mathrm{k}-$ HTS current leads, 1 - carbon-fiber tubes, $m$ - voltage taps, $\mathrm{n}$ - thermal bridges, o - connections between pancake coils.

and impregnated using epoxy resin. The total length of the HTS tape is $1621 \mathrm{~m}$. The inductance of the magnet is about $1 \mathrm{H} \mathrm{[4].}$

The temperature about $13 \mathrm{~K}$ allows the magnet to operate at the maximal (critical) current of $264 \mathrm{~A}$, which gives the maximal storage energy of around $34.8 \mathrm{~kJ}$. The maximal tested current, due to limitation of power supply unit, was $173 \mathrm{~A}(13 \mathrm{~K})$, which gives the storage energy of $15 \mathrm{~kJ}$. The magnet of this SMES will operate under 


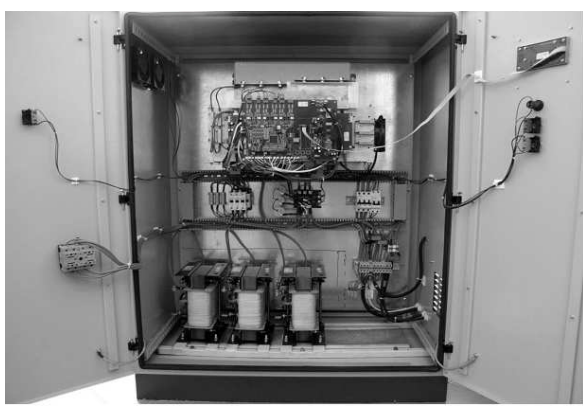

Fig. 2. The power conditioning system for SMES.

control of the electronic power converter (PCS) (Fig. 2) with limitation to $180 \mathrm{~A}$ that corresponds to $16.2 \mathrm{~kJ}$.

Currently, superconducting magnetic energy storage devices are seen primarily as assistive devices for industrial controlling power systems. Due to the high costs of construction and operation the SMES systems are individually designed for specific applications.

\section{Superconducting fault current limiter}

Superconducting fault current limiters (SFCL) are electric devices used to limit current faults in electric power networks [6]. The SFCLs use a phenomenon unique to superconductors - the transition into the resistive state. Figure 3 shows the relation of superconductor resistivity to current density during the superconductor transition to the resistive state: very low resistivity below $J_{c}$, very steep rise of resistivity in the proximity of $J_{c}$ and considerable resistivity above $J_{c}$.

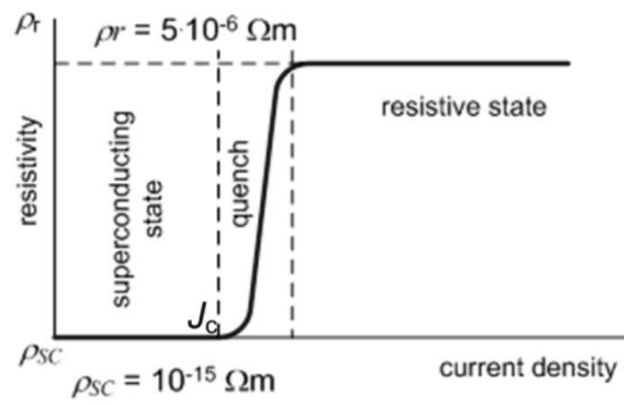

Fig. 3. Relation of superconductors resistivity to current density during the superconductor transition to the resistive state.

This increase of resistivity during resistive state can be unitized directly either to limit the current or only to use it as a signal that the current crossed a certain value in the system.

An increase of current caused by the occurrence of a short-circuit current, or an increase of the superconductor temperature, causes transition of the superconducting material from the superconducting state into the resistive state. This increases the impedance of short-circuit loop, allowing a decrease of the short-circuit current value. Figure 4 shows the wave forms of rated current and shortcircuit currents with and without limitation effects.
Designs of the SFC limiters have been known for years, but it was only thanks to the recent developments of the technology of manufacturing of superconductors that enabled their realization and practical implementation. Layered, yttrium-based HTS $2 \mathrm{G}$ tapes offer resistivity at the temperature of liquid nitrogen, i.e. $77 \mathrm{~K}$, which is enough to build limiters of high currents and voltages.

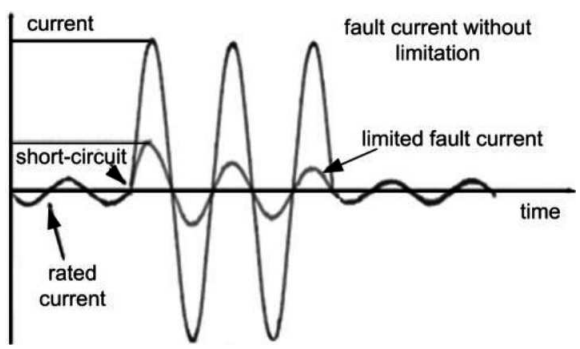

Fig. 4. Limitation of short-circuit current by the SFC limiter.

Superconducting fault current limiters utilize nonlinear elements in the form of superconducting windings, instead of electronic electro-mechanical or pyrotechnic components. Its module construction allows the use of superconducting fault current limiters for various voltage and current values. Unlike a high-voltage fuse, a SFCL does not switch the line off at the moment of the occurrence of a short-circuit but simply limits the shot-circuit current to a given value. After the occurrence of a shortcircuit current, a SFCL must be momentarily switched off and cooled so that it can return to the superconductive state. It is normally from several seconds to several minutes, depending on the design of the device, after which the limiter may return to its nominal work in the network and react again to another short-circuit. Compact in design, a SFC limiter provides operation conditions very close to ideal. In nominal operation conditions, a SFCL is not visible in the power network, and during a short-circuit it automatically reduces the short-circuit current, regardless of its value.

Superconducting fault current limiters which are to be used in power networks are designed to secure the devices of the power network against dynamic and thermal effects of a short-circuit. Due to the point of their installation in the power network, SFCLs can be classified as linear and bus tie, independent of the working voltage. They also may be installed in incoming and outgoing sides.

There are two basic types of designs of superconducting fault current limiters: resistive and inductive [7], Fig. 5.

In the resistive type SFCL, the element that limits the short-circuit current is made of a $2 \mathrm{G}$ superconducting tape of proper length which is wound as a bifilar winding, or of a superconducting module made of many straight pieces of the $2 \mathrm{G}$ superconducting tape connected in parallel. During a short-circuit in a power network, the superconducting element in the resistive limiters must very quickly transit from the superconducting state to the resistive state in order to avoid a local overheating of the superconducting tape. The superconducting element of 


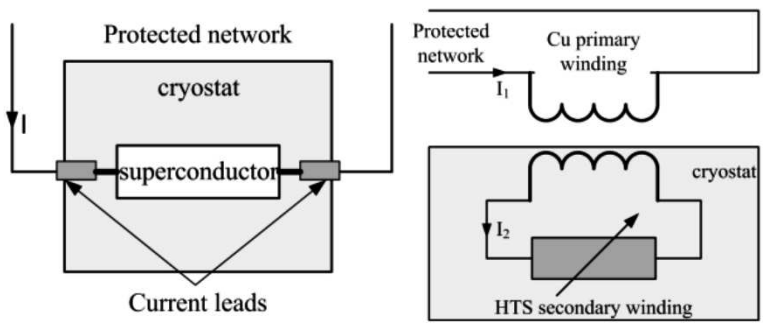

Fig. 5. Superconducting fault current limiter: resistive (a) and inductive (b).

the resistive limiter is additionally protected by a resistor connected in parallel which limits the current in the superconducting element during the occurrence of a shortcircuit, Fig. 5a.

Inductive type SFCL consists of a superconducting winding and a conventional copper winding placed over the superconducting winding, Fig. 5b. During work in nominal conditions, the core is screened because the flux from the primary winding is compensated by the flux from the shorted secondary superconducting winding. During a short-circuit, induced current in the shorted superconducting winding increases. The induced current in the secondary winding exceeds the critical current of the superconductor and the superconducting winding transits to the resistive state. The resistance of the secondary winding causes a substantial reduction of the flux compensation from the primary winding. The impedance of the limiter depends on the core. On switching off of a short-circuit, the limiter must return to the superconducting state at the nominal current.

A limiter with a saturated core uses non-linear characteristics of the magnetizing of the core in order to change the impedance, and the superconducting winding is powered with direct current to magnetize the core. During working at the nominal current, the saturated core causes the limiter to have low impedance. During a short-circuit, an increase of current in the winding of a conventional limiter causes the core to leave the sat-

TABLE II

Selected SFCL projects carried out in Europe.

\begin{tabular}{c|c|c|c|c}
\hline \hline country/ & Germany & Italy & Poland & EU \\
year $/$ & 2009 & 2010 & 2010 & 2012 \\
coord. & Nexans & ESRS & Electr. Inst. & Nexans \\
\hline type & resistive & resistive & inductive & resistive \\
\hline voltage & $12 \mathrm{kV}$ & $9 \mathrm{kV}$ & $6 \mathrm{kV}$ & $24 \mathrm{kV}$ \\
\hline \multicolumn{5}{c}{ current } \\
\hline rated & $0.8 \mathrm{kA}$ & $0.25 \mathrm{kA}$ & $0.7 \mathrm{kA}$ & $1.005 \mathrm{kA}$ \\
max. fault & $63 \mathrm{kA}$ & - & $20 \mathrm{kA}$ & - \\
\hline limit & $30 \mathrm{kA}$ & - & $5 \mathrm{kA}$ & - \\
\hline HTS & Bi-2212 & $1 \mathrm{G} \mathrm{tape}$ & $2 \mathrm{G} \mathrm{SF12050}$ & YBCO \\
material & profiles & Bi2223 & YBCO & YBCO \\
\hline weight & $2.5 \mathrm{t}$ & $3.8 \mathrm{t}$ & $0.4 \mathrm{t}$ & -
\end{tabular}

uration and an increase of the limiter impedance. In a saturated core limiter, the superconducting winding does not transit to the resistive state.

The SFCLs are the subject of studies in many research centres around the world. These researches have led to the invention of several designs and prototypes of SCFL units. The characteristics of some of them are presented in Table II.

Recently in Laboratory of Superconducting Technologies in Lublin there has been developed and built inductive type coreless superconducting fault current limiter [2]. Light and compact construction of the limiter consists of three magnetically coupled windings cooled in liquid nitrogen: primary and secondary windings, made of HTS $2 \mathrm{G}$ tape, and a parallel connected primary copper winding. A high magnetic coupling between the superconducting primary and secondary windings allow to eliminate the core and gives a low voltage drop on the limiter at a nominal current. The presented solution reduces

TABLE III

Parameters of the $15 \mathrm{kV} / 140$ A SFCL.

\begin{tabular}{c|c|c}
\hline \hline Parameter & \multicolumn{2}{|c}{ Value } \\
\hline nominal voltage & $U_{n}$ & $15 \mathrm{kV}$ \\
nominal current & $I_{n}$ & $140 \mathrm{~A}$ \\
voltage on the limiter $I_{n}$ & $U_{\mathrm{SCFL}}$ & $<1 \mathrm{~V}$ \\
prospective peak current & $I_{\text {peak }}$ & $40 \mathrm{kA}$ \\
first peak limiting & $I_{\mathrm{p}}$ & $5 \mathrm{kA}$ \\
operating temperature & $T$ & $77.4 \mathrm{~K}$ \\
weight of the limiter & $m$ & $150 \mathrm{~kg}$
\end{tabular}
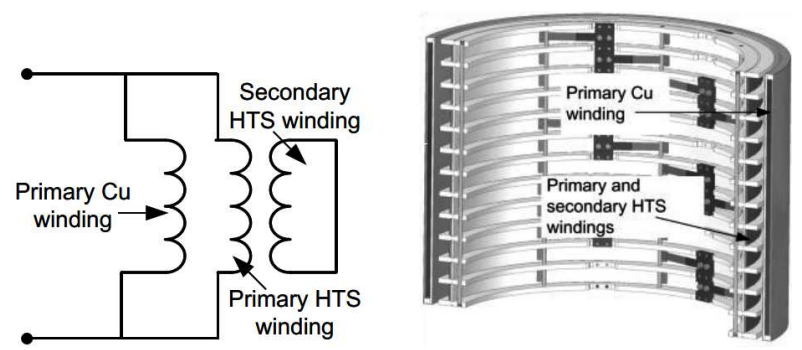

Fig. 6. Electrical circuit and scheme of the SFCLs windings connections.

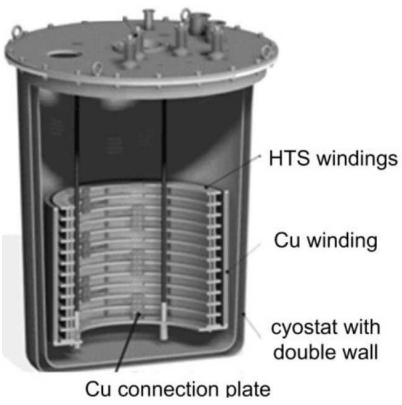

Fig. 7. Three-windings coreless SFCL 15 kV/140 A. 
the size and the weight of the device. The configuration of the windings and the design of the three-windings coreless SLC are shown in Fig. 6 and Fig. 7. Parameters of the limiter are given in Table III.

Currently in Laboratory of Superconducting Technologies there has been realized another research project as a part of the program GEKON 2, in which there will be designed and built coreless superconducting fault current limiter $25 \mathrm{kV} / 500 \mathrm{~A}$.

\section{Superconducting transformers}

Nearly all the electricity generated on Earth is three to five times processed in transformers of power system. A simplified diagram of the power grid is shown in Fig. 8.

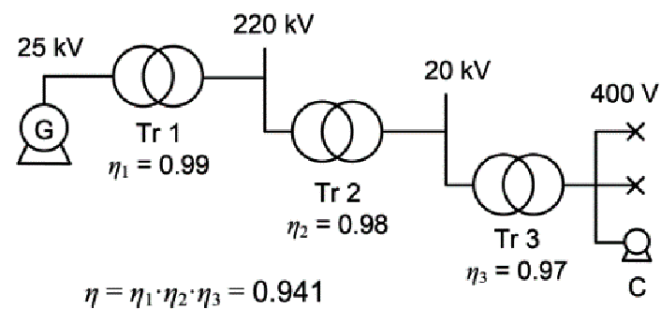

Fig. 8. Simplified diagram of the power grid.

Despite the high efficiency of transformers $\operatorname{Tr} 1, \operatorname{Tr} 2$, $\operatorname{Tr} 3,5-10 \%$ of the electric energy is lost on the way from the generator $\mathrm{G}$ to the consumers $\mathrm{C}$ depending on the power factor. Most of these losses are created in the transformer windings typically made of copper.

Attempts to use windings made of LTS (e.g. Nb-Ti) in the 70s and the 1G HTS in the 90's of the twentieth century did not yield the expected results. Obviously, the application of liquid nitrogen for the winding cooling reduced refrigeration costs. The fibrous structure of $1 \mathrm{G}$ HTS wires is inspired by low-temperature superconducting materials. Thin superconductor fibers are placed in a metal matrix made of copper, bronze, or silver. Due to the eddy currents, this configuration causes large energy loss when alternating current is transported.

In the first decade of the twentieth century a technology of high-temperature superconductor coated conductors (HTS CC, 2G HTS) was developed. Their rapid commercialization has created new possibilities for the use of superconductors in high-power AC devices such as transformer.

Superconducting transformers bring new challenges regarding design and operation [8, 9]. The design of the magnetic circuit, superconducting winding optimization, the choice of cooling method may be mentioned here. The superconducting windings generate AC losses, which affect the power of the cooling system and thus the efficiency of the device. Because of the dynamic forces and stresses in the windings, the mechanical durability and allowable current density becomes an important issue. The choice of the superconducting wire in respect of its resistivity in the resistive state (at cryogenic temperatures) is equally important.
TABLE IV

Parameters of the selected superconducting transformers.

\begin{tabular}{c|c|c}
\hline \hline Year & Company, country & Basic parameters \\
\hline 2003 & ABB & 3 -phase, 100 MVA, \\
& Switzerland & $225 / 20 \mathrm{kV}$, HTS 1G \\
\hline 2005 & Hyundai HI & 3 -phase, 60 MVA, \\
& South Korea & $154 / 23 \mathrm{kV}$, HTS 2G \\
\hline 2007 & Kyushu Electric & 3 -phase, 20 MVA \\
& Power/Japan & $66 / 6.9 \mathrm{kV}$, HTS 2G \\
\hline 2007 & KESRI Ministry & 1 -phase, 100 MVA \\
& of Commerce, Industry & $154 / 22.9 / 6.6 \mathrm{kV}$ \\
& and Energy/South Korea & HTS 1G \\
\hline \multirow{2}{*}{2011} & Industrial Research Ltd & 3 -phase, 1 MVA \\
& New Zealand & $11 / 0.42 \mathrm{kV}, \mathrm{HTS} 2 \mathrm{G}$
\end{tabular}

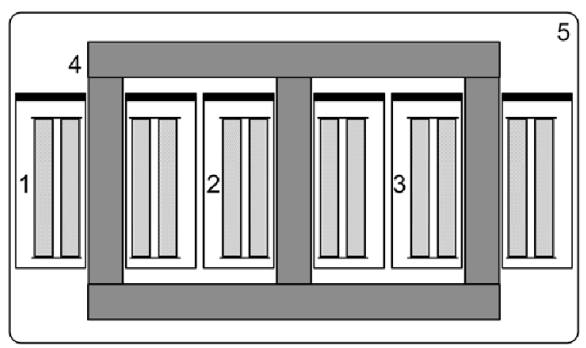

Fig. 9. Explanatory drawing of the cross-section of 3phase superconducting transformer.

Table IV shows the characteristics of the selected designs of the superconducting transformers.

The construction of the three-phase superconducting transformer resembles conventional unit. To reduce heat emission in the cryostat and due to unfavorable changes in the properties of typical ferromagnetic materials at low temperatures, the best solution is to use so-called warm magnetic core operating at ambient temperature.

A sketch showing the structure cross-section is depicted in Fig. 9 [10].

Cryostats 1, 2, and 3 maintain the cryogenic temperature of the phase windings of the transformer. The magnetic core 4 operates at room temperature. Thus, it does not differ from those used in conventional transformers. The device is enclosed in an environmental casing 5 protecting the structure from external influences. Different in relation to the standard transformer the cooling system of the superconducting windings is shown in Fig. 10.

Lower-voltage winding 1 and upper-voltage winding 2 belonging to the same transformer phase are arranged in a cryostat 3 filled with liquid nitrogen at slightly elevated pressure. Each phase cryostat is made of a composite material in the toroidal shape of rectangular cross-section and is placed on the magnetic core limb 4. In order to reduce heat exchange, empty space between the cryostat walls must be filled with cryo-insulation. Usage of glass microspheres maintained at a high vacuum is proven experimentally. This solution guarantees a very good insulating properties. Heat generated in the windings and en- 


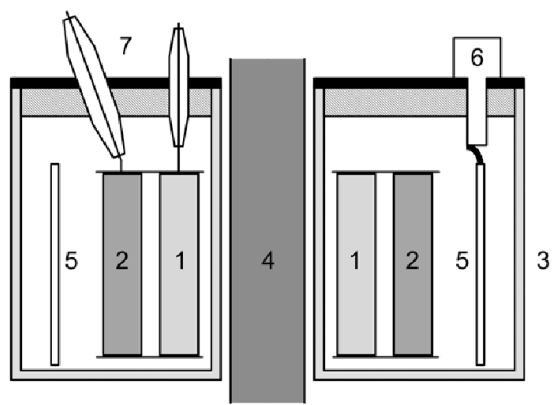

Fig. 10. Idea of the cooling system for superconducting transformer windings.

tering into the cryostat is removed by a thermal shield 5 connected to the cryocooler cold head 6 . There are three cryocooler-assisted liquid nitrogen cooling subsystems one per cryostat. Current leads 7 and the winding holders are mounted at the cryostat lid. Warm transformer core 4 operates above $300 \mathrm{~K}$. It is cooled by forced air or liquid circulation.

Beside minimization of cryogen loss, the main advantage of the cryocooler-assisted system is the ability to control the winding temperature. This allows the cooling to a temperature in the range of 65 to $77 \mathrm{~K}$ in the case of liquid nitrogen at atmospheric pressure. So-called critical current lift factor has a value of two - for $2 \mathrm{G}$ HTS critical current at $65 \mathrm{~K}$ is twice higher than its value at $77 \mathrm{~K}$. Thus, a well-designed cooling system allows the stable operation of superconducting windings under long-term overload with a relatively small increase in energy losses and low output voltage regulation.

Liquid nitrogen is a material of good insulating properties, non-flammable, environmentally benign, easy to obtain and relatively cheap. Replacement of transformer oil with liquid $\mathrm{N}_{2}$ limits environmental burden and eliminates risk of contamination due to fire or explosion. Indoor operation of superconducting transformer is not a significant danger. It may be used in compact transformer station or on board of a ship. Comparing with conventional oil-cooled design, nitrogen refrigeration becomes more resistant to any kind of incidents, such as technical or natural disasters, the effects of military conflicts or terrorist attacks.

A properly designed superconducting transformer in addition to electric energy conversion can simultaneously play the role of a fault current limiter [11]. In the case of current of a magnitude exceeding the critical value for the winding, the superconducting material will switch to a resistive state. Current will be redirected to normal metal layers. Additional resistance will appear in the shortcircuit path. Reduction of the short-circuit current, and hence of mechanical loads acting on windings in emergency situations, promotes the lighter construction, less material consumption and easier to transport structure. However, proper selection of film thickness and resistivity of the metal layers of superconducting tapes becomes an important aspect. Parameters of these layers deter- mine the winding resistance in resistive state, thermal capacity, and thus the peak value of the fault current, the allowed fault time and the after-fault cooling period.

Short-circuit current limiting feature of the transformer is based on the transition of superconductor to the resistive state. That is why a short-circuit reactance of the transformer can be designed at a very low level. Good insulating properties of liquid nitrogen, much better than the transformer oil, also contribute to it. This allows to reduce the radial spacing between upper- and lower-voltage windings and to reduce the leakage flux. It results in a limitation of output voltage fluctuations under variable load. Therefore, it becomes possible to simplify or even to eliminate a complicated voltage control subsystem. This is particularly important in the case of windings placed in the cryostats. Adverse phenomena, that normally occur during power-up of the transformer with reduced short-circuit reactance, do not appear in full in the case of superconducting device. This fact is determined by the intrinsic limiting feature of inrush current as well.

\subsection{HTS transformer windings}

Because of the critical current value, single superconducting tape permits to build experimental transformers of low power. The superconducting windings of high power unit must be made using several parallel $2 \mathrm{G}$ HTS tapes. This requirement, in addition to the obvious relation with the critical current value of a single conductor, is dictated by a direct connection between the width of the tape and the level of AC losses. Wide tapes (40 mm) are available, but their use causes an increase in AC losses which is difficult to accept.

Due to the different inductances and the unequally distributed leakage flux, the parallelization of superconducting tapes can create high circulating currents. The uneven current distribution in parallel branches can lead to the values exceeding the critical current of superconductor. Sharp increase of losses may result in winding damage due to overheating.

In order to solve problem mentioned above, a solution proposed by Roebel is adapted [10]. It has been utilized in conventional windings for many decades. It relies on the continuous transposition of parallel wires. HTS tape cannot be bent like a normal copper conductor. That is why narrow and suitably shaped strips are cut from wide HTS tape. They are isolated and interlaced into a continuously transposed cable (CTC), Fig. 11.

HTS CTC (Fig. 12a) conductors are commercially available. Currently, due to limited market and the lack of competition, its biggest drawback is a very high price. CTC superconducting wire is about three times more expensive than simple parallel system without the continuous transposition made for the same critical current.

An alternative possibility of limiting losses in the windings made of parallel strips may be their local (incomplete) transposition. A discrete device - tape interconnector TI - is used (Fig. 12b). Computer simulations 


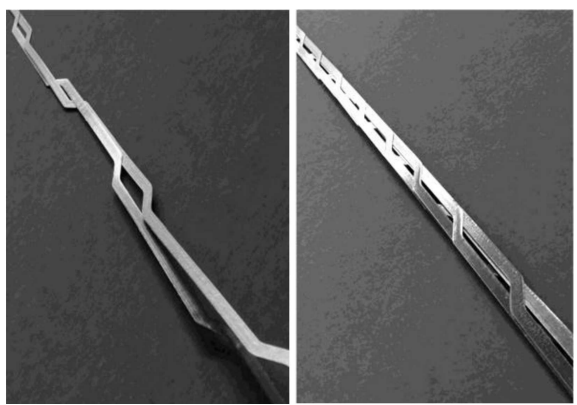

Fig. 11. CTC made of 2G HTS tapes.

confirm correctness of such a solution for two, three, and four parallel conductors [12].

a)

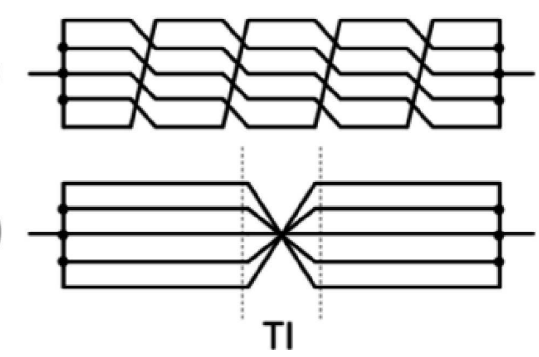

Fig. 12. Parallel wire transposition: (a) full transposition, (b) partial transposition with interconnector TI.

\subsection{HTS transformer cost}

Comparison of basic properties for conventional threephase 50 MVA, 110/15 kV transformer and its superconducting counterpart is shown in Table $\mathrm{V}$.

TABLE V

Comparison of the parameters for 50 MVA conventional transformer and its HTS counterpart at $100 \%$ load.

\begin{tabular}{l|c|c}
\hline \hline Parameter & $\begin{array}{c}\text { Copper } \\
\text { winding }\end{array}$ & $\begin{array}{c}\text { HTS } \\
\text { winding }\end{array}$ \\
\hline core mass [t] & 28.86 & 26.48 \\
copper wire mass [t] & 7.08 & \\
HTS tape mass [t] & & 0.351 \\
core losses [kW] & 41.46 & 38.09 \\
winding losses [kW] & 245.61 & 46.86 \\
total losses [kW] & 287.07 & 84.96 \\
transformer efficiency, & 99.287 & 99.788 \\
cos $\varphi=0.8 \quad$ & \\
short-circuit voltage [\%] & 11.7 & 3.4
\end{tabular}

HTS windings of 50 MVA transformer will be lighter by $6.7 \mathrm{Mg}$ than copper windings. Mass of the superconducting tape will be $351 \mathrm{~kg}$ only (4.96\% of copper mass).

Taking into account the efficiency of the cryocoolers, total losses of HTS transformer at $100 \%$ load amount to $85 \mathrm{~kW}$. It is $29.6 \%$ of total losses of copper winding transformer neglecting the cost of forced oil cooling. Assuming continuous operation of the transformer under full load, this gives an annual energy savings of $1.77 \mathrm{GWh}$.
Relatively low short-circuit voltage of the HTS transformer will pose no problem due to its ability to limit short-circuit current.

The influence of HTS tape width on a simple payback time is shown in Table VI. It should be noted that the unit price is not proportional to the tape width, nor to the critical current value. A narrower tape allows for greater energy savings. Despite this, taking into account the total length of the winding material and its present unit price, it turns out that a more economical solution is to use a wider tape.

TABLE VI

Influence of HTS tape width on selected parameters of superconducting transformer

\begin{tabular}{l|c|c}
\hline \hline \multirow{2}{*}{ Parameter } & \multicolumn{2}{|c}{ HTS tape width } \\
\cline { 2 - 3 } & $4 \mathrm{~mm}$ & $12 \mathrm{~mm}$ \\
\hline $\begin{array}{l}\text { number of parallel tapes for upper } \\
\text { voltage winding }\end{array}$ & 9 & 3 \\
\hline $\begin{array}{l}\text { number of parallel tapes for lower } \\
\text { voltage winding }\end{array}$ & 48 & 16 \\
\hline aggregated HTS tape length [m] & 103883 & 34604 \\
\hline unit price of HTS tape [USD/m] & 85 & 130 \\
\hline total HTS winding cost [mln USD] & 8.83 & 4.50 \\
\hline energy saving per year [GWh] & 1.94 & 1.77 \\
\hline simple payback time [year] & 67.30 & 39.10 \\
\hline $\begin{array}{l}\text { simple payback time at the HTS } \\
\text { tape price 20 USD/kAm [year] }\end{array}$ & 2.30 & 3.60 \\
\end{tabular}

At unit price $130 \mathrm{USD} / \mathrm{m}$ of SCS 12050 (12 mm wide) superconducting tape, the winding material for designed superconducting transformer will cost approximately 4.5 million USD. By comparison, winding copper with a mass of $7.08 \mathrm{Mg}$ would cost about 110 thousand USD at a unit price of $15 \mathrm{USD} / \mathrm{kg}$.

The superconducting winding cost must be enlarged by the cryocooler price. These devices must be able to dissipate a total heat load of $3.12 \mathrm{~kW}$ at $77 \mathrm{~K}$. An estimated unit price is $100 \mathrm{USD} / \mathrm{W}$, this gives a cost of about 312 thousand USD. It should be noted that the superconducting winding is so expensive that additional equipment of HTS transformer can be disregarded in this approximate analysis.

The price of electricity produced in a gas turbine block is estimated in the range of $5.3-8.3$ cents $/ \mathrm{kWh}$. Assuming an average value of 6.8 cents/kWh, HTS transformer can help to save 120.4 thousand USD yearly. This means that a simple payback period of three-phase superconducting transformer 50 MVA $132 / 13.8 \mathrm{kV}$ made of the 2G HTS tape SCS12050 is just over 39 years at presentday conditions.

Figure 13 depicts a comparison of total energy losses for 50 MVA conventional (copper windings) transformer and HTS transformer.

Due to the almost same masses and working conditions of magnetic cores, the energy losses in idle state are comparable. Superconducting technology reveals its 


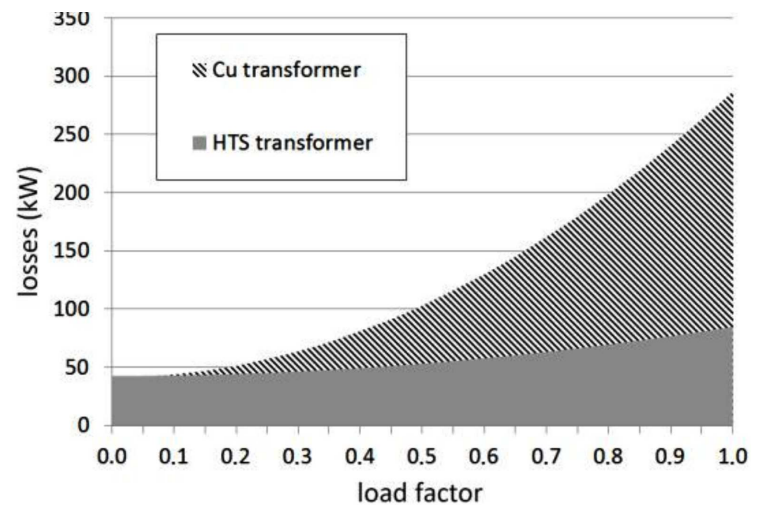

Fig. 13. Comparison of power losses in copper winding transformer and HTS transformer $(\cos \varphi=1)$.

true potential with the increasing load of the transformer - when the winding currents are close to the rated values.

Distribution of energy losses in transformers at full load is shown in Fig. 14. For the superconducting device the largest share have cryocooler losses. Cryogenic cooling technology is developing at a rapid pace. This allows to assume that the efficiency of these devices will be further improved and the advantage of HTS technology will be even more explicit.

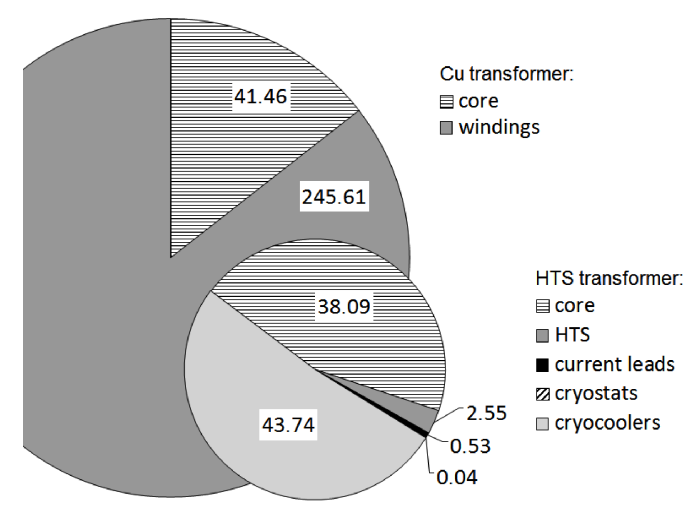

Fig. 14. Distribution of 50 MVA transformer losses (area proportional to losses in $\mathrm{kW}$ ).

\section{Conclusion}

Currently available LTS and HTS winding wires enable the construction of power devices, i.e. energy storage systems (SMES), current limiters (SFCL) and transformers with parameters, which are unattainable using copper windings.

Superconducting energy storage systems (SMES) accumulate energy in magnetic field produced by the current of the coreless superconducting electromagnet. Since the coil current is direct, they may be made of HTS or LTS wires. So far, energy of constructed devices is too small to stabilize power grid. SMESs have found their application in the protection of sensitive equipment from power failures (UPS).
Because transformers and fault current limiters work at 50 or $60 \mathrm{~Hz}$, effective application of superconductors was possible after 2007, when HTS coated conductors of layered structure were commercialized (2G YBCO). Research on SFCLs is very advanced, many demonstration devices working in power grid have been built. The most promising solution is a three-winding coreless SFCL built in the Electrotechnical Institute in Warsaw [2]. Superconducting transformer is the biggest challenge. Driven by the possibility of load loss elimination, focus was centered on high-power devices (50 MVA, 63 MVA), where benefits can be the greatest. At current prices of $2 \mathrm{G}$ HTS tapes and CTC cables, simple payback time is too long for high-power units.

Besides the minimization of winding losses, 2G HTS transformers have the ability to limit fault currents, higher overload endurance, lower output voltage regulation and they are non-flammable. These properties of 2G HTS transformers can increase the connected power of the grid. The shortage of it inhibits the development of renewable and distributed energy sources. Power of the transformer at a distribution station does not exceed 1 MVA in most cases. Available 2G HTS tapes allow to build transformer windings without the use of CTC. Therefore, it is necessary to focus on such devices and their cooling systems.

\section{References}

[1] L. Hyoungwoo, Ch. Gueesoo, L. Ji-Kwang, R. KyungWoo, IEEE Trans. Appl. Supercond. 17, 1951 (2007).

[2] M. Majka, J. Kozak, S. Kozak, G. Wojtasiewicz, T. Janowski, IEEE Trans. Appl. Supercond. 25, 5601005 (2015).

[3] G. Wojtasiewicz, T. Janowski, S. Kozak, B. Kondratowicz-Kucewicz, M. Majka, J. Phys. Conf. Ser. 97, 012019 (2008).

[4] J. Kozak, M. Majka, S. Kozak, T. Janowski, IEEE Trans. Appl. Supercond. 20, 1344 (2010).

[5] J.X. Jin, W. Xu, X.Y. Chen, X. Zhou, J.Y. Zhang, W.Z. Gong, A.L. Ren, Y. Xin, IEEE PES ISGT Asia 2012, 1569554057 (2012).

[6] M. Noe, M. Steurer, Supercond. Sci. Technol. 20, R15 (2007).

[7] G. Wojtasiewicz, B. Kondratowicz-Kucewicz, Przeglad Elektrotechniczny 85, 177 (2009).

[8] S.S. Kalsi, Applications of High Temperature Superconductors to Electric Power Equipment, IEEE Press, Wiley, 2011.

[9] A. Morandi, L. Trevisani, P.L. Ribani, M. Fabbri, L. Martini, M. Bocchi, J. Phys. Conf. Series 97, 012318 (2008); L. Jaroszyński, T. Janowski, Przegląd Elektrotechniczny 90, 164 (2014).

[10] N. Glasson, M.P. Staines, Z. Jiang, N.S. Allpress, IEEE Trans. Appl. Supercond. 23, 5500206 (2012).

[11] G. Wojtasiewicz, T. Janowski, S. Kozak, J. Kozak, M. Majka, B. Kondratowicz-Kucewicz, IEEE Trans. Appl. Supercond. 23, 5500505 (2012).

[12] L. Jaroszyński, T. Janowski, Przegląd Elektrotechniczny 10, 284 (2015). 